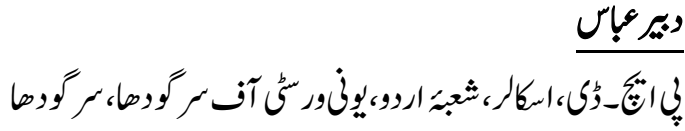

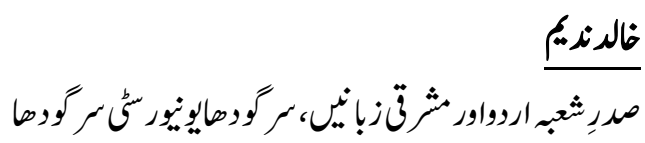

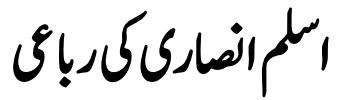

Dabir Abbas

Ph. D Scholar, Department of Urdu, University of Sargodha, Sargodha.

\title{
Khalid Nadeem
}

Chairman Department of Urdu \& Oriental Languages, University of Sargodha, Sargodha.

\section{Aslam Ansari's Quartet}

Aslam Ansari is a prominent contemporary Urdu poet. As well as being a poet, he is also considered as an important Iqbal Shanaas, researcher and critic. He has not only shown creative excellence in Urdu but has also written excellent poetry in Persian, English and Saraiki. In Urdu, not only he has written Ghazal and Nazm, but a fair number of quartrains are his poetic assets. He aslso successfully experimented with writing the first Urdu blank verse quartrains (Rubaaiyat-e-Muarra). This study involves purposive sampling and for that purpose number of his quartrains have been selected and analysed. The purposive samples have been analysed with qualitive method of analysis. The qualitative method serves the desired purpose of poetic analysis and new meanings have been found with unique literary, linguistic, stylistic, dramatic and poetic features.

Keywords: Aslam Ansari, Poetry, Quartrain, Rubaaiyat-e.Muarra, Subject, Style.

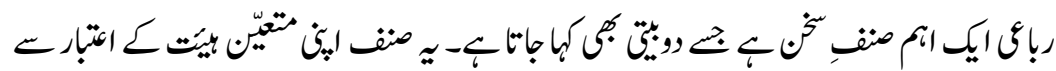

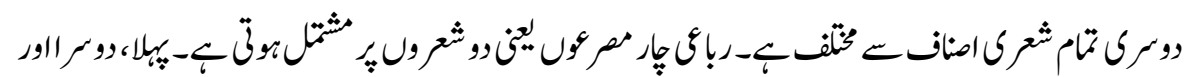

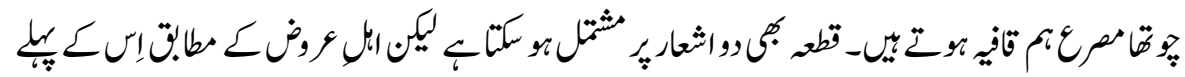




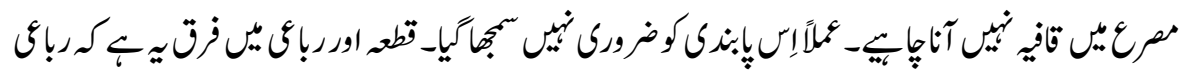

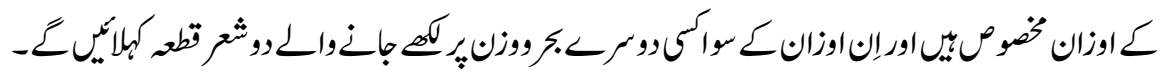

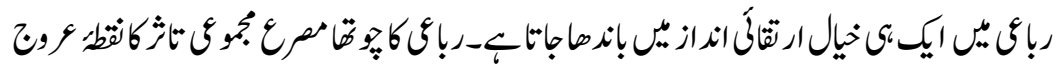

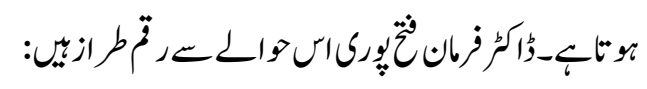

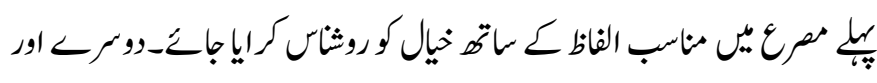

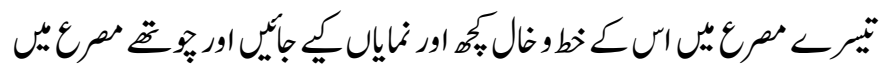

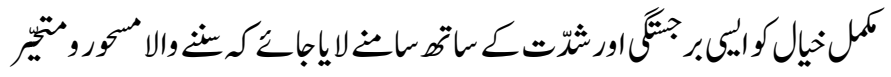

$$
\text { (1) }
$$

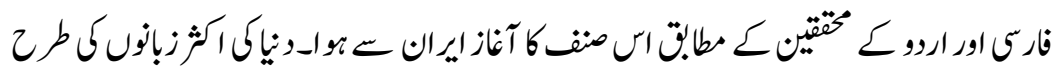

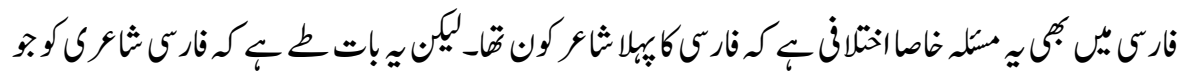

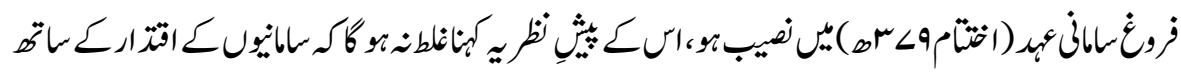

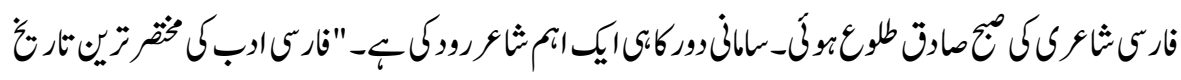

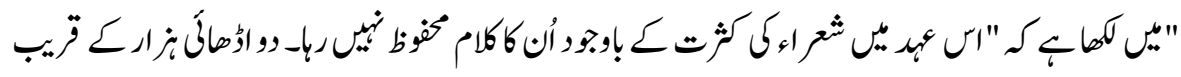

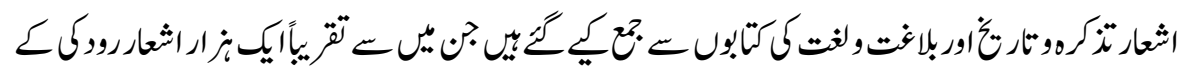

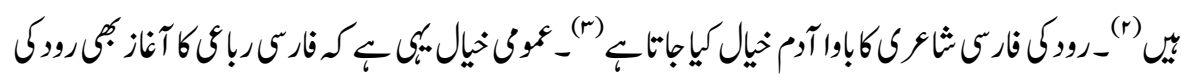

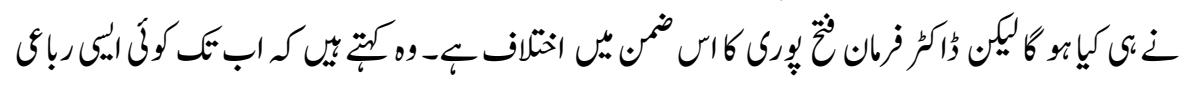

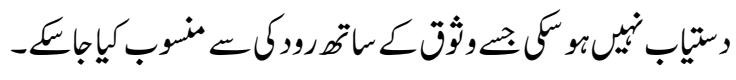

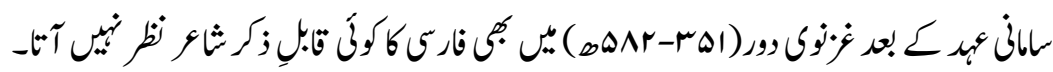

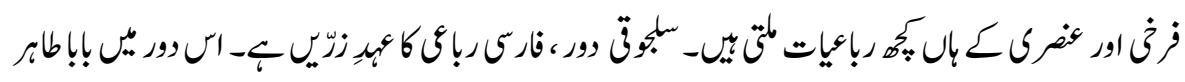

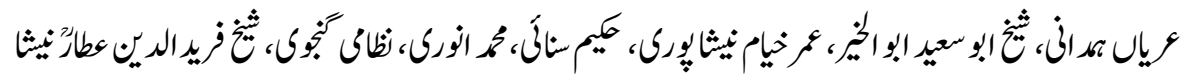

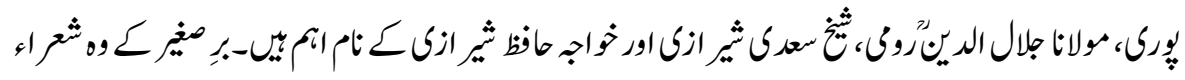

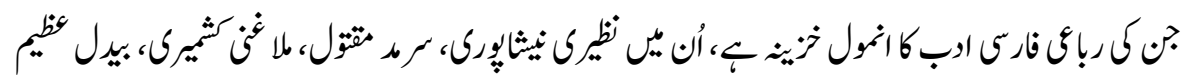

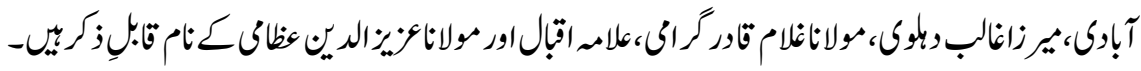




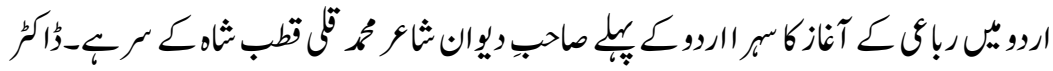

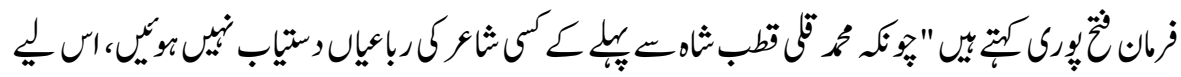

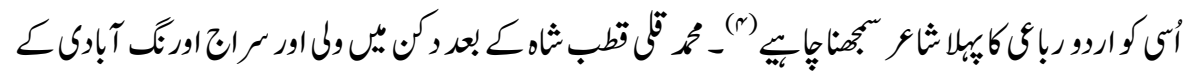

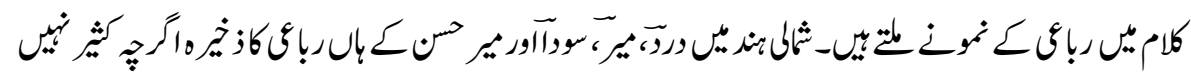

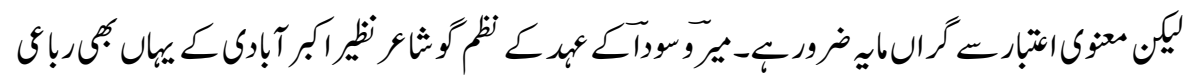

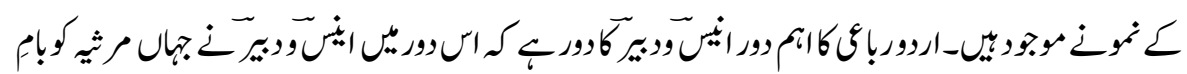

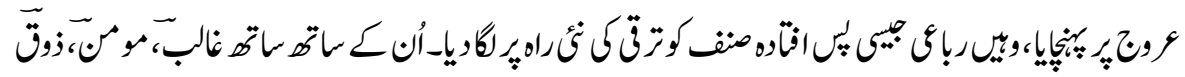

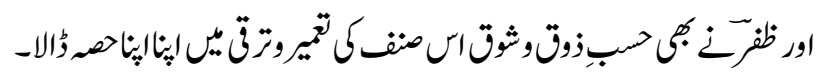

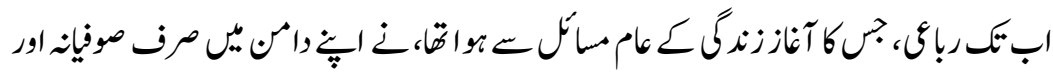

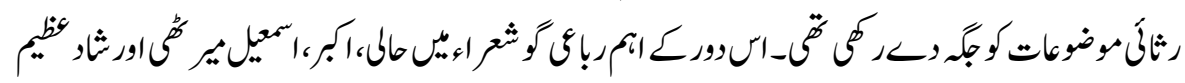

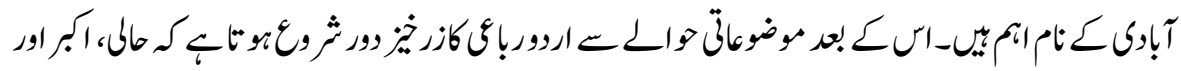

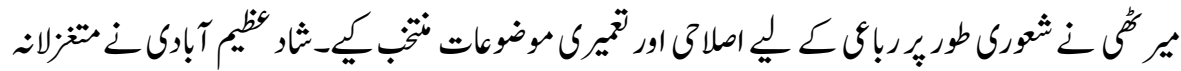

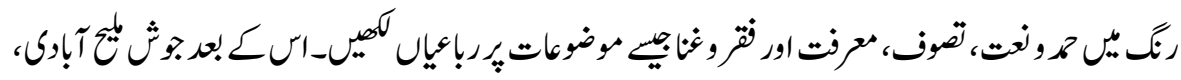

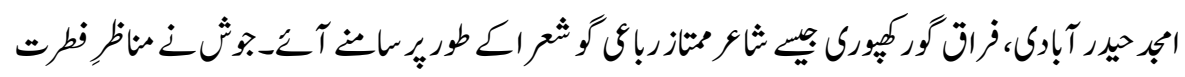

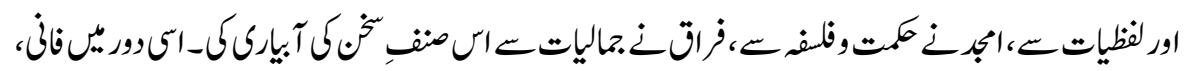

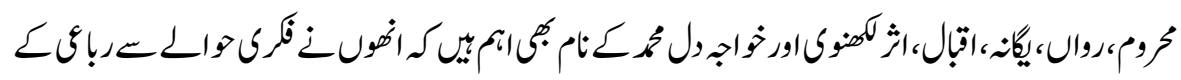

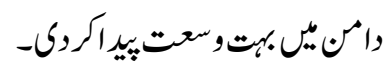

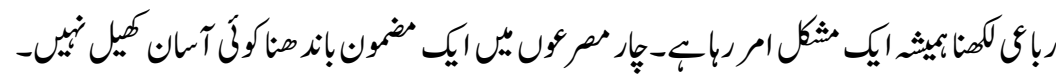

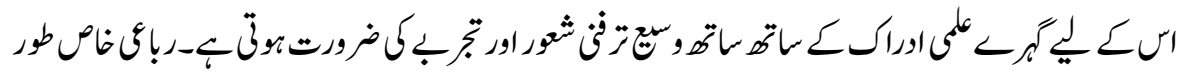

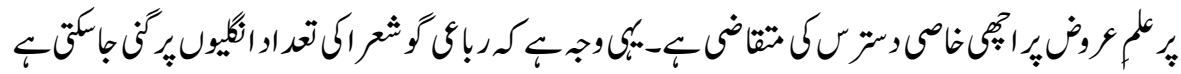

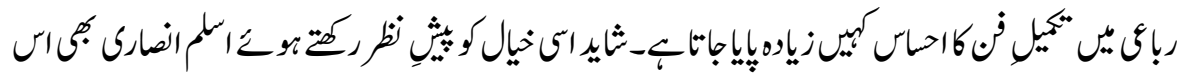

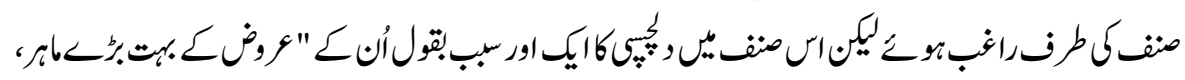




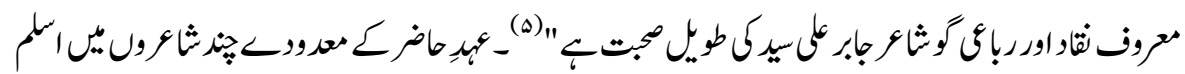

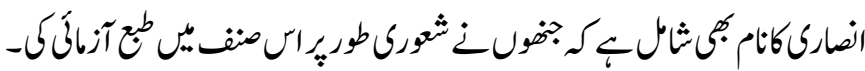

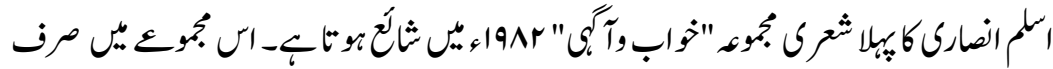

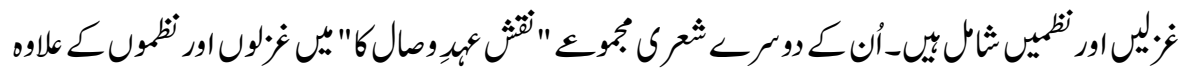

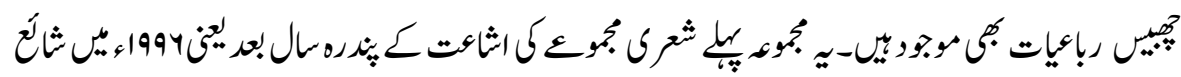

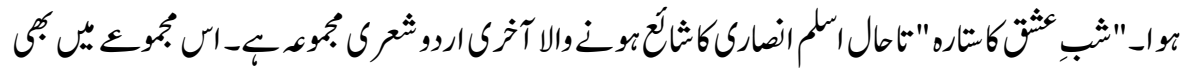

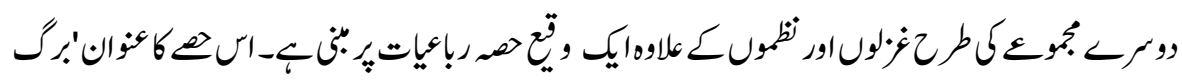

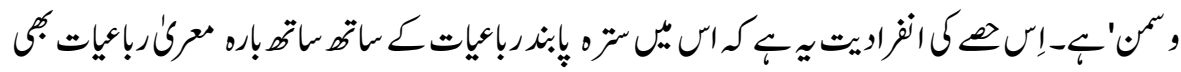

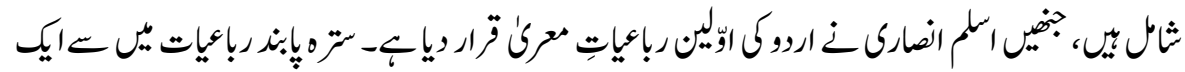

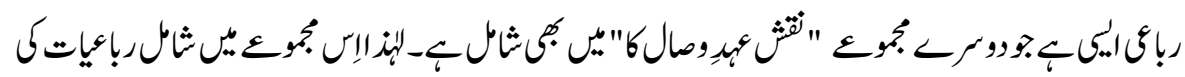

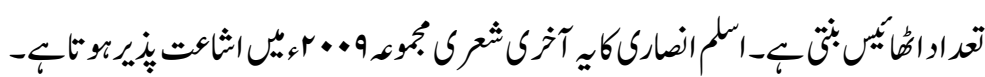

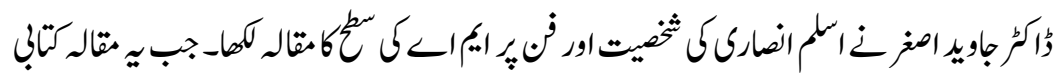

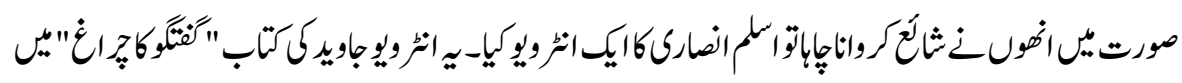

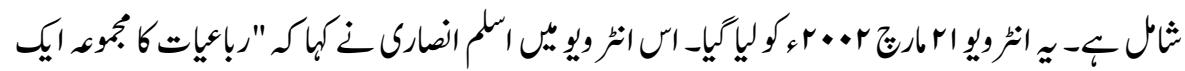

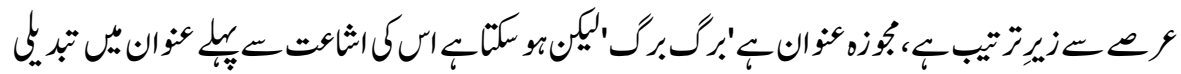

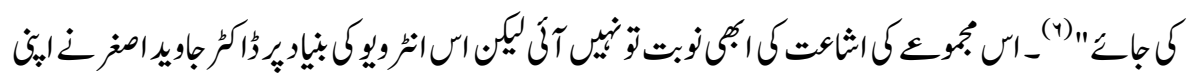

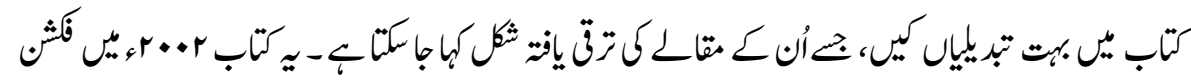

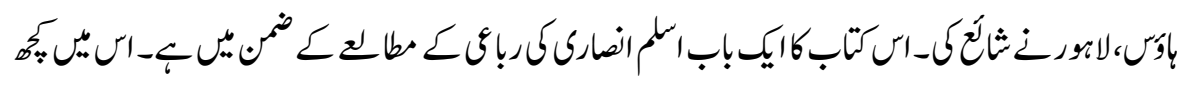

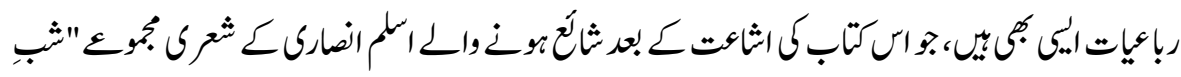

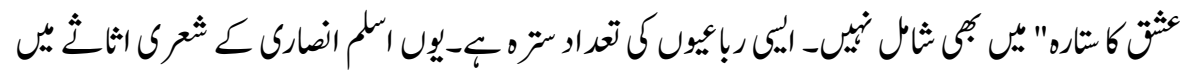

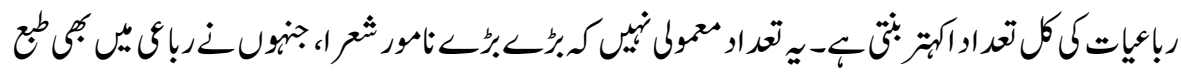

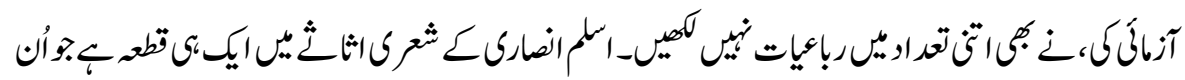

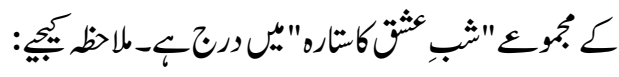




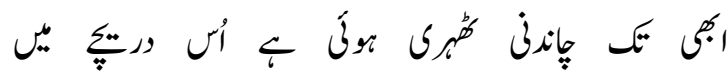

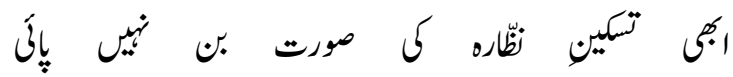

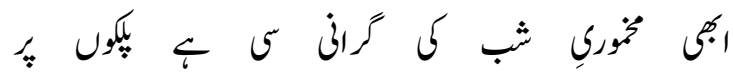

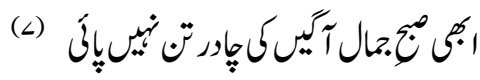

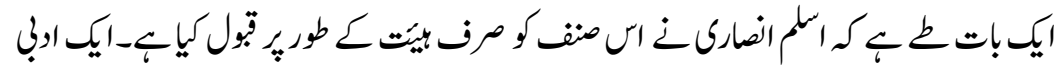

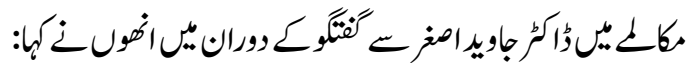

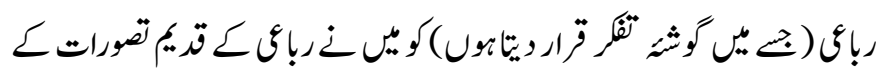

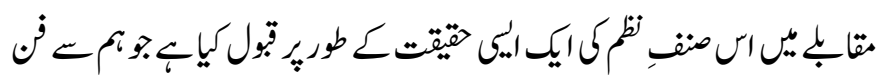

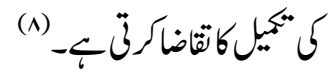

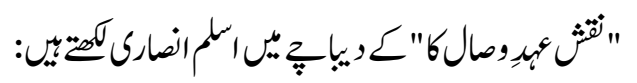

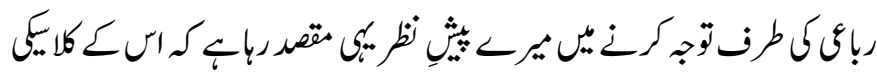

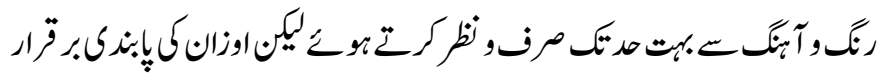

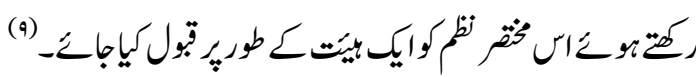

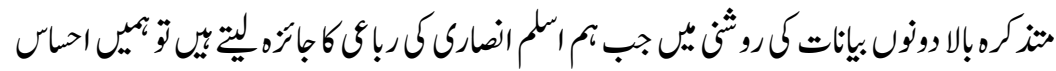

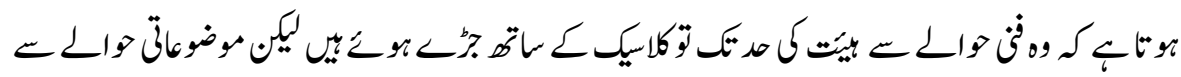

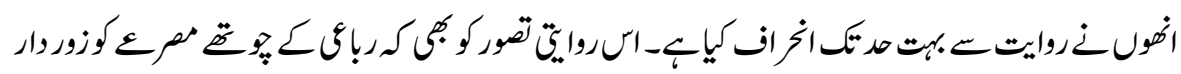

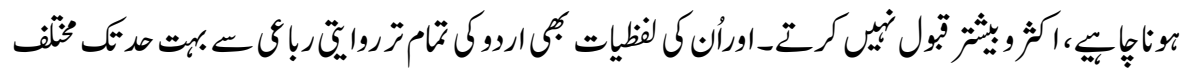

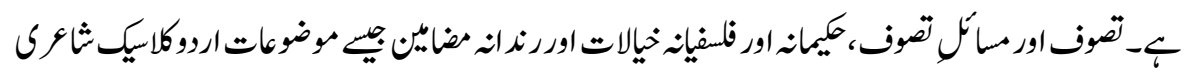

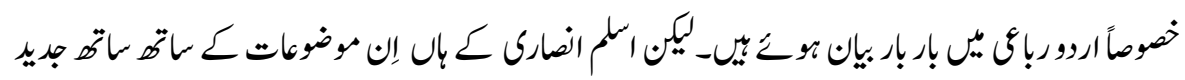

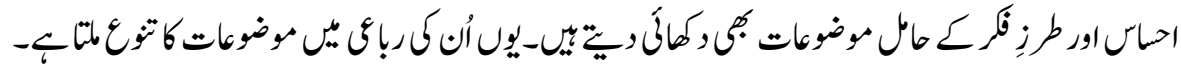

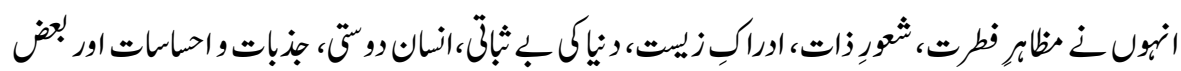

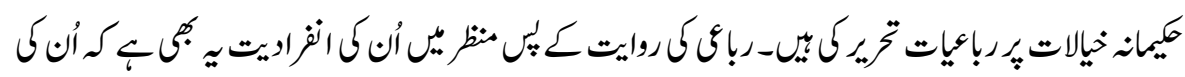

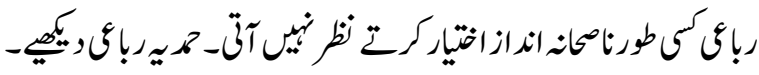


ISSN (Print): 2709-9636 | ISSN(Online) : 2709-9644 | ISSN-L : 2709-9636

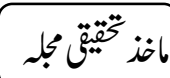

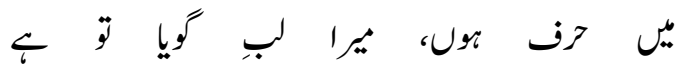

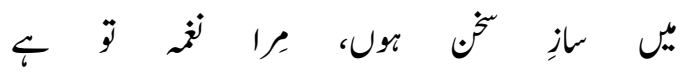

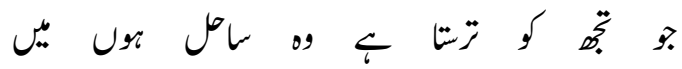

$$
\begin{aligned}
& \text { (1.) }
\end{aligned}
$$

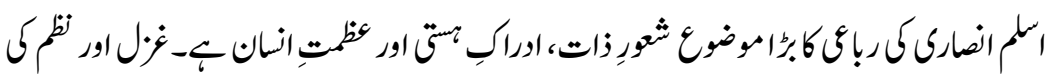

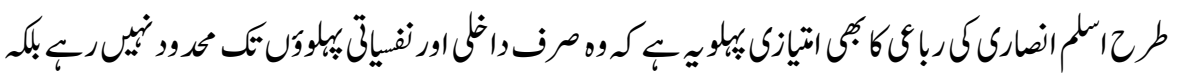

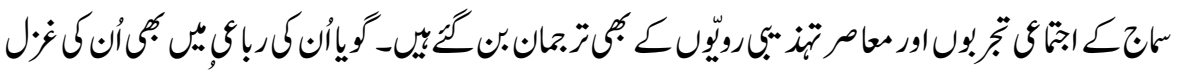

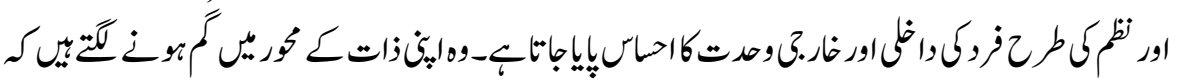

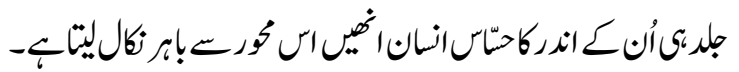

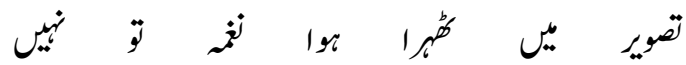

أوالو

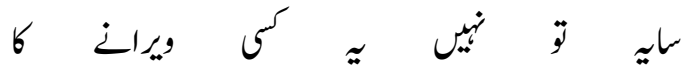

(11)

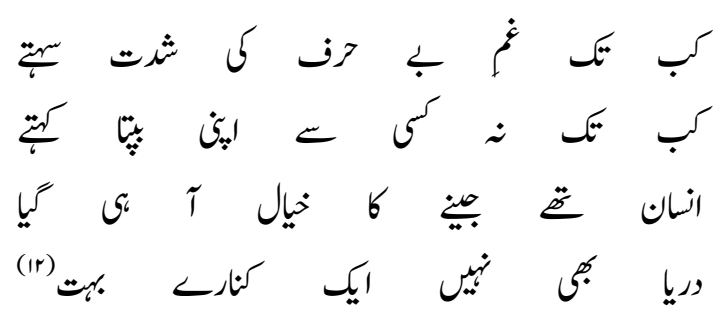

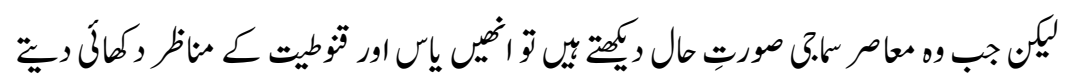

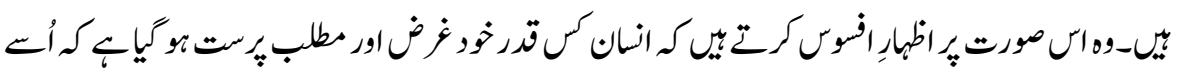

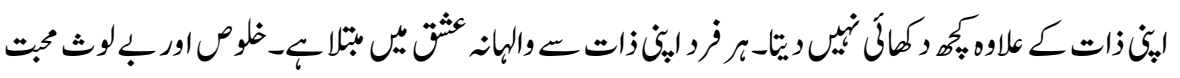

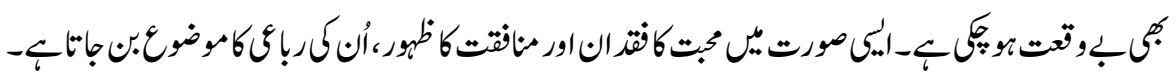




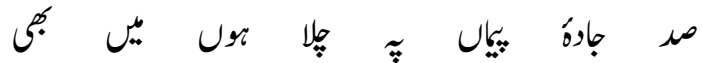

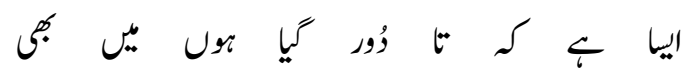

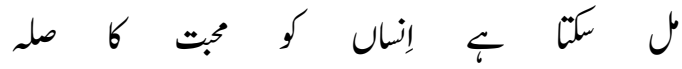

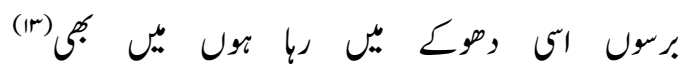

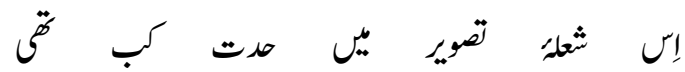

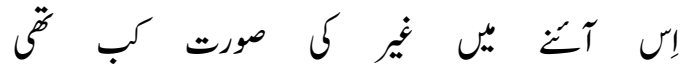$$
\text { ال }
$$

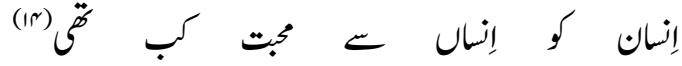

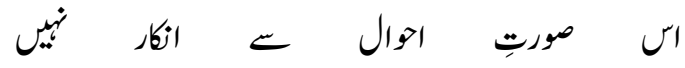

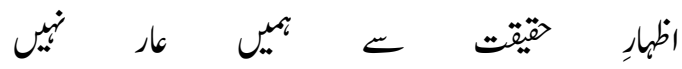

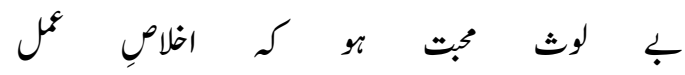$$
\text { (10) }
$$

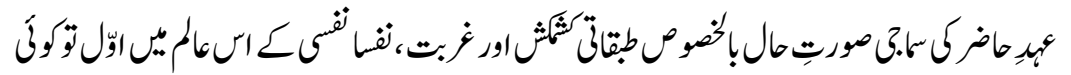

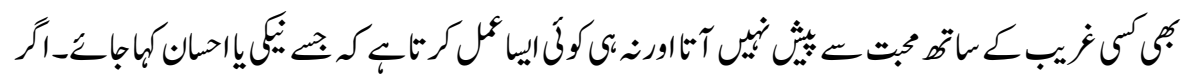

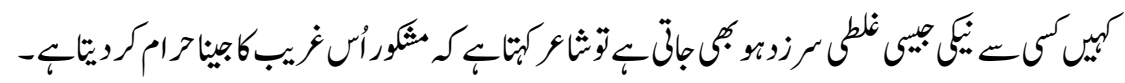

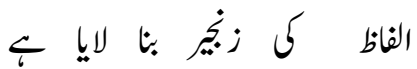

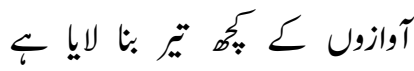

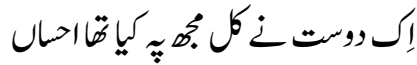

$$
\begin{aligned}
& \text { آنج أن كى وهثير بنا لايا بـ }
\end{aligned}
$$




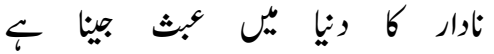

$$
\begin{aligned}
& \text { خ }
\end{aligned}
$$

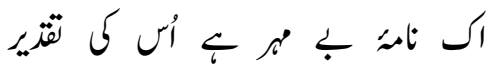

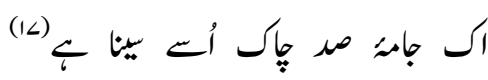

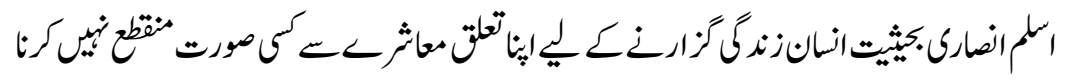

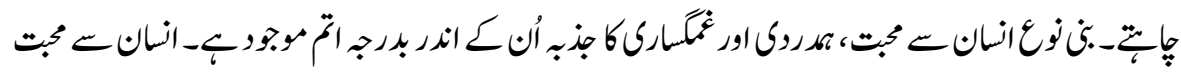

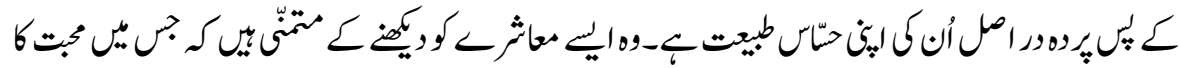

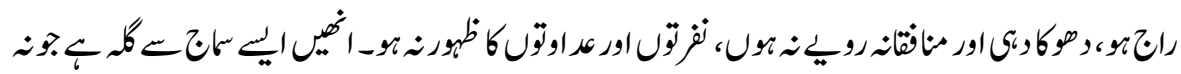

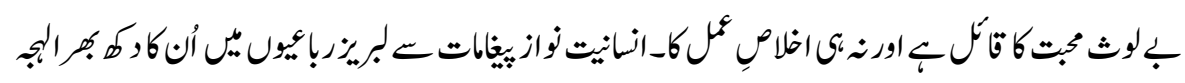

ملإسيجي

$$
\begin{aligned}
& \text { اوراك ع آنَّة كو ميال ن كرو }
\end{aligned}
$$

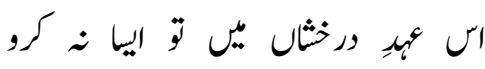

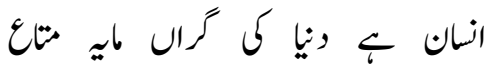

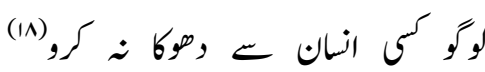

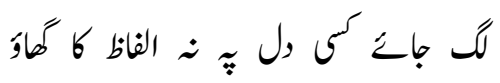

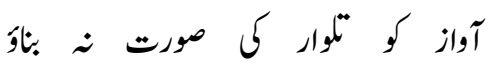

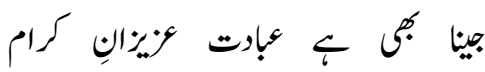

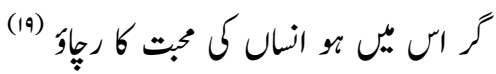

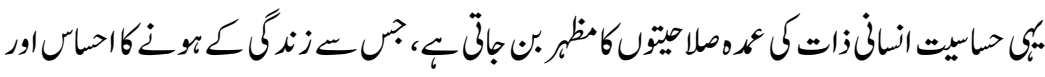

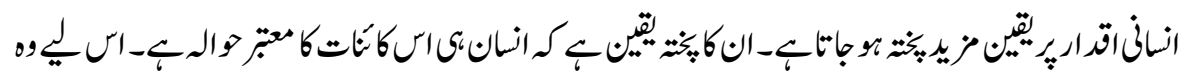

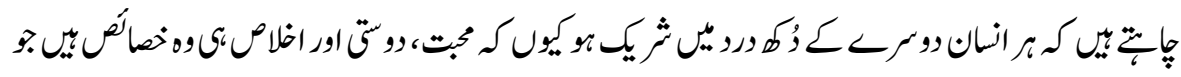


ISSN (Print): 2709-9636 | ISSN(Online) : 2709-9644 | ISSN-L : 2709-9636

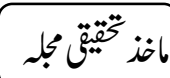

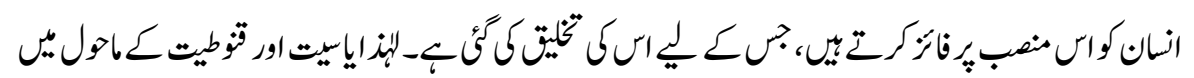

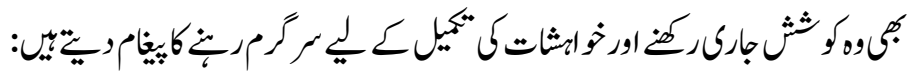

رثئ

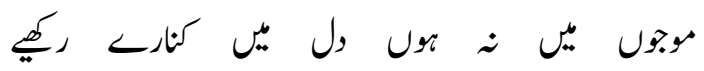

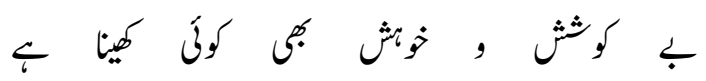

(r.)

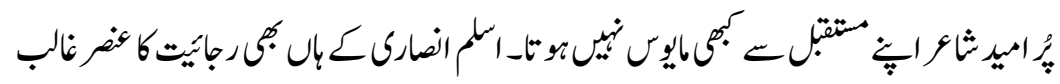

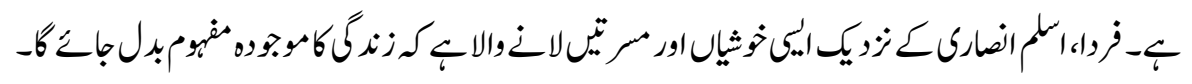

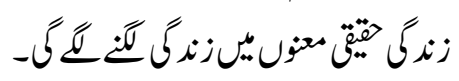

تنيقيق

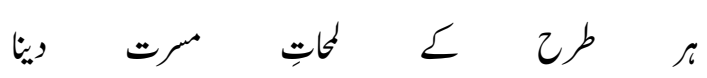

زرا،

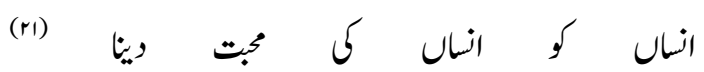

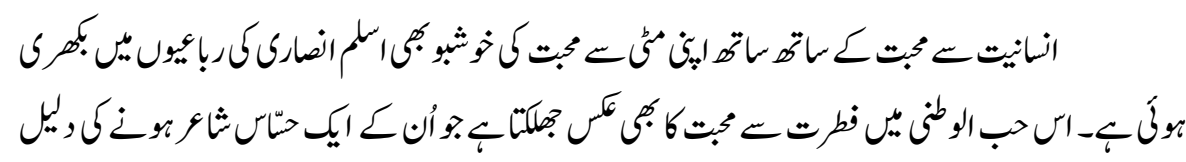

بُ

$-4$

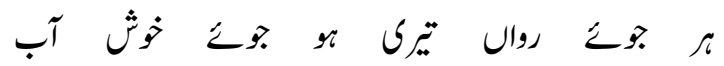

مر

(rr)

4r 


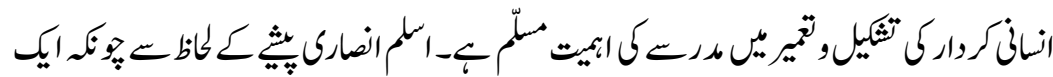

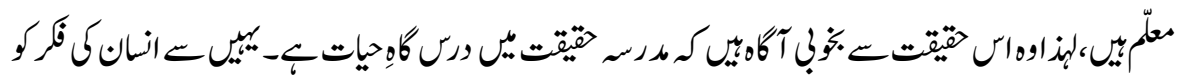

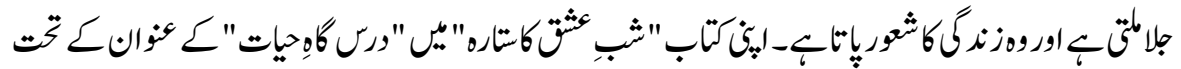

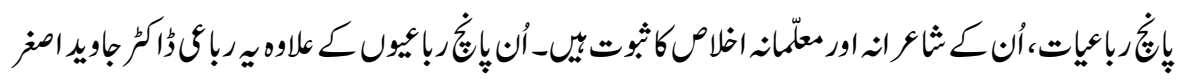

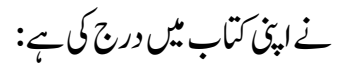

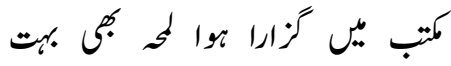

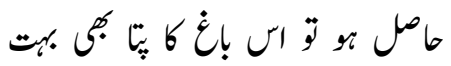

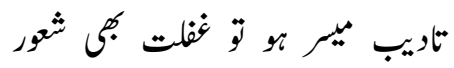

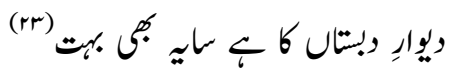

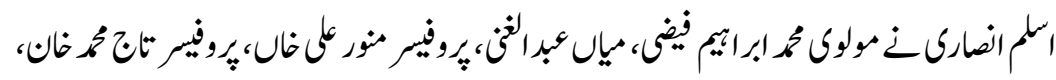

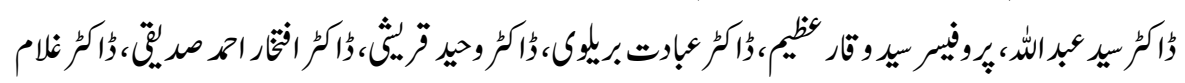

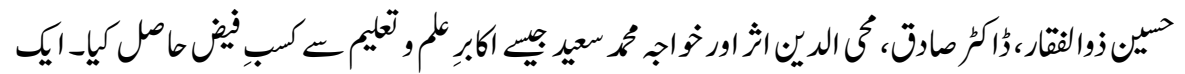

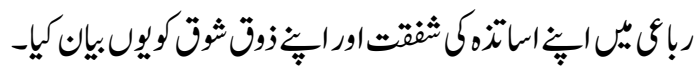
التار مت سب ميرك كريم اور ثنيق

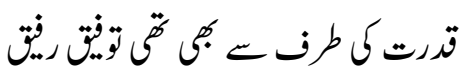

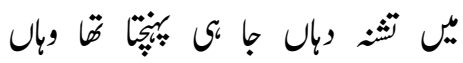

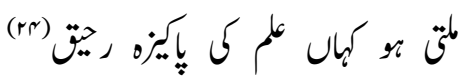

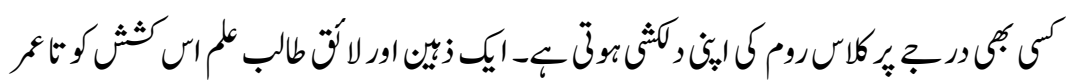

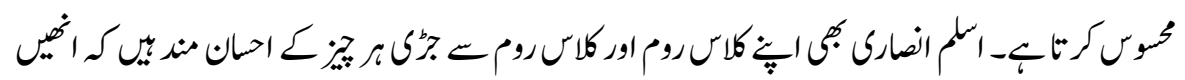

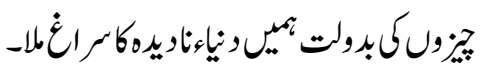

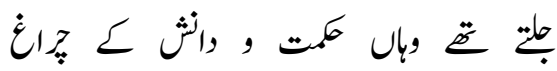

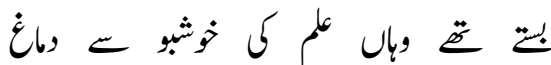


ISSN (Print): 2709-9636 | ISSN(Online) : 2709-9644 | ISSN-L : 2709-9636

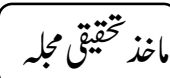

وه وُيكس، وه روبرم، وه وُمر، وه الطات

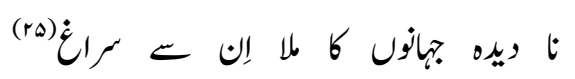

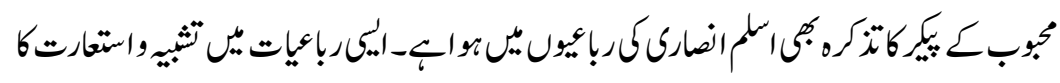

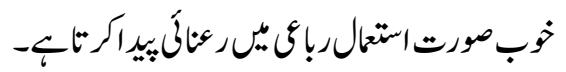

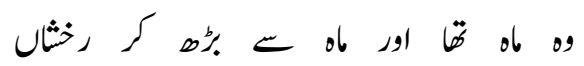

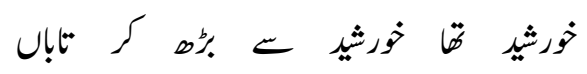

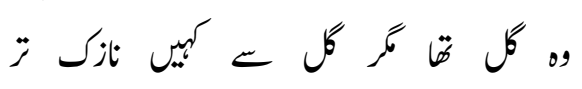

(r)

要

ز

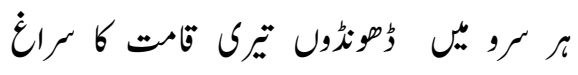

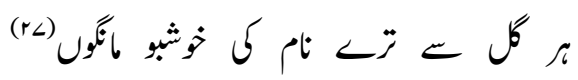

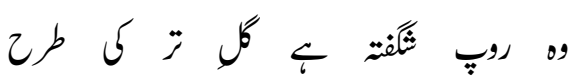

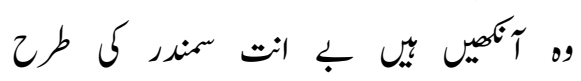

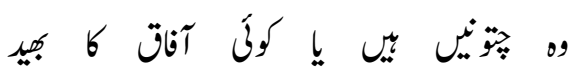

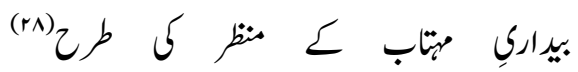

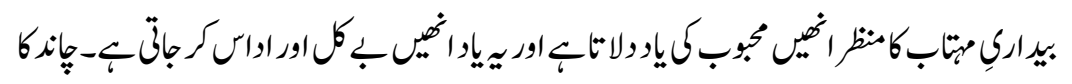

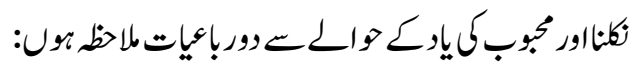

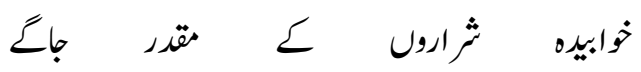

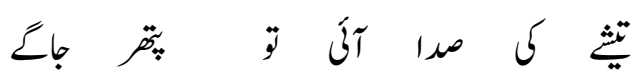

40 
ISSN (Print): 2709-9636 | ISSN(Online) : 2709-9644 | ISSN-L : 2709-9636

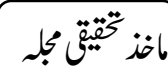

اكل يائ

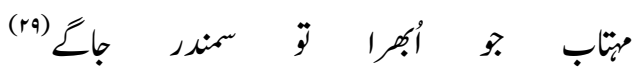

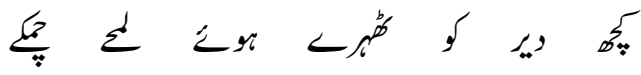

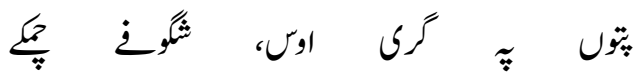

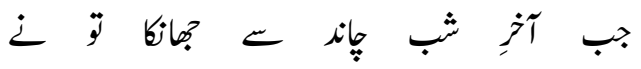

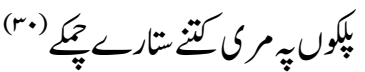

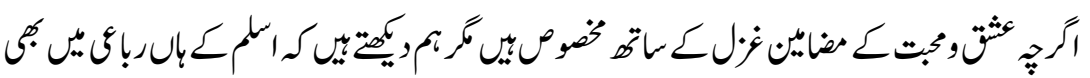

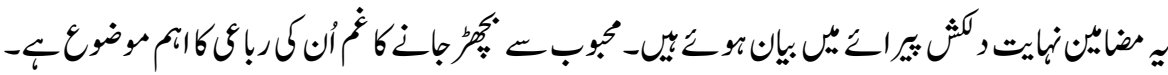

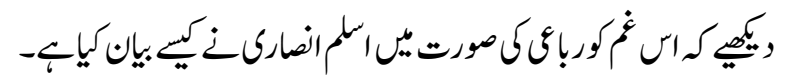

ثان

C

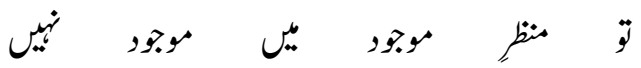

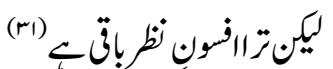

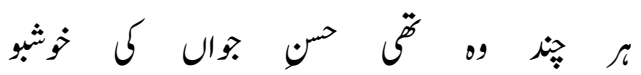

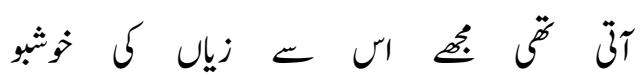

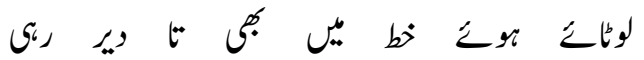

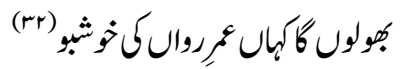

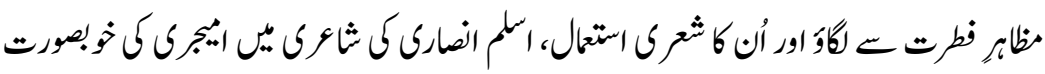

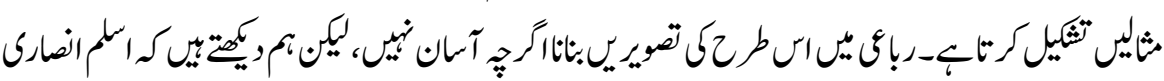

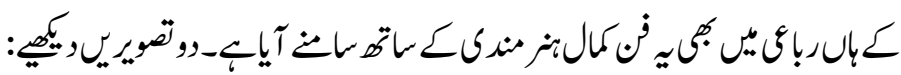

44 


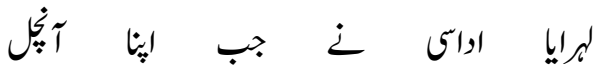

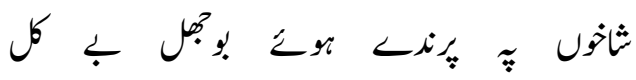

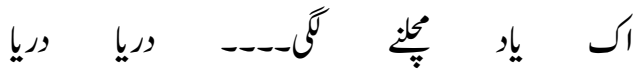

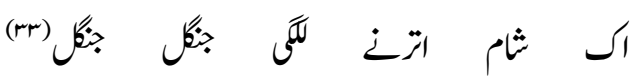

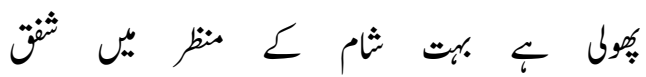

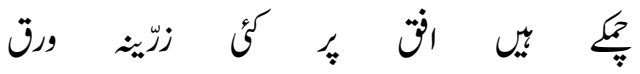

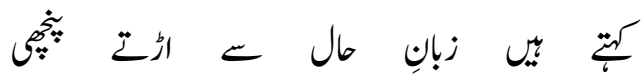

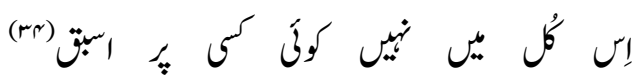

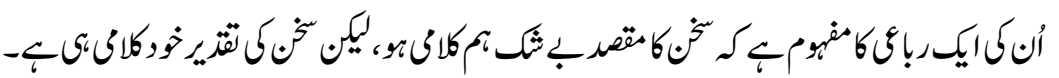

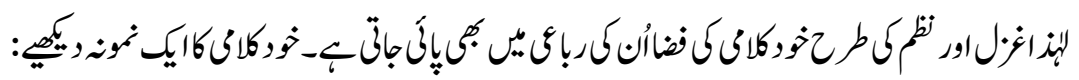

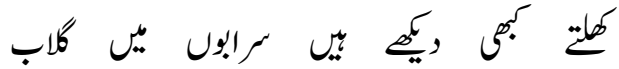

$$
\begin{aligned}
& \text { بكا }
\end{aligned}
$$

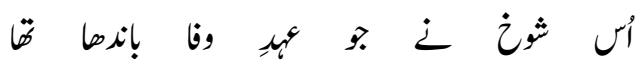

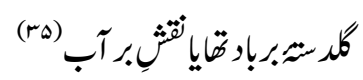

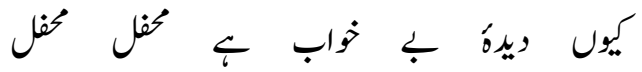

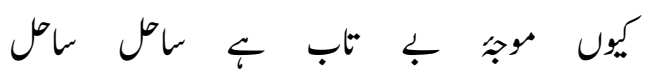

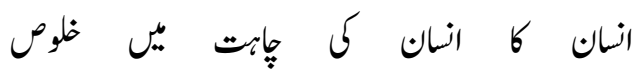

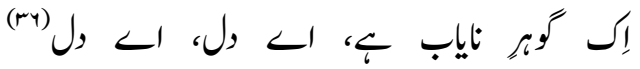

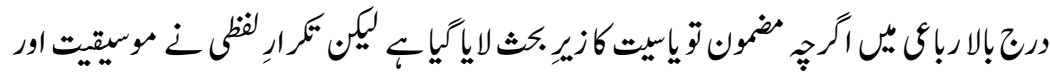

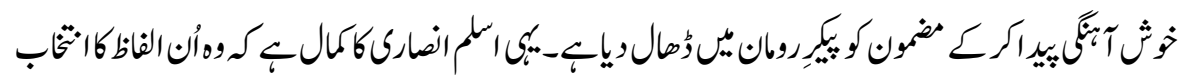


ISSN (Print): 2709-9636 | ISSN(Online) : 2709-9644 | ISSN-L : 2709-9636

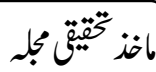

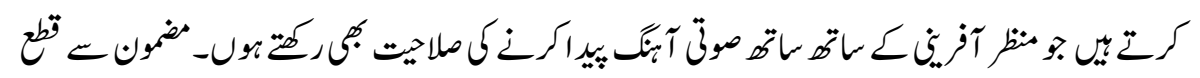

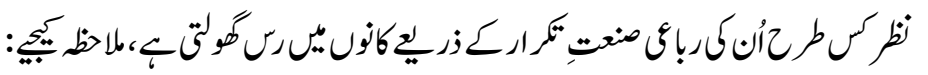

ز

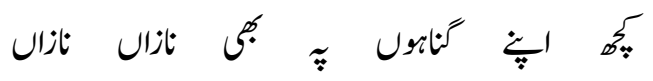

بـ

ك ك

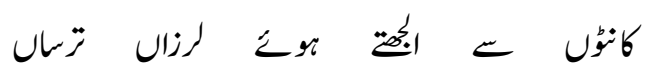

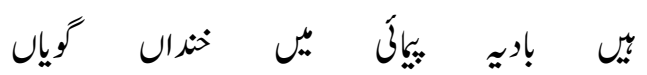

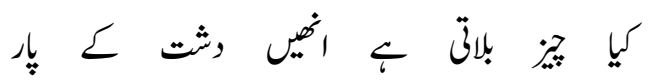

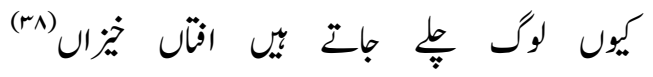

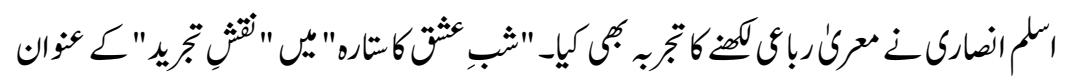

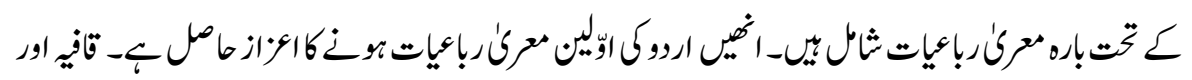

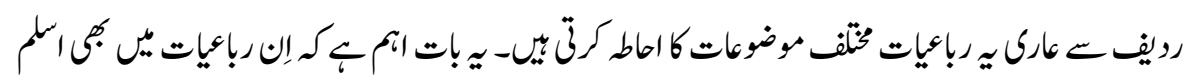

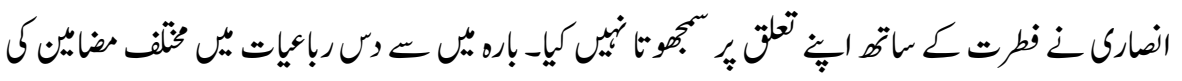

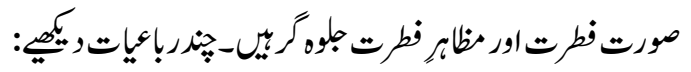

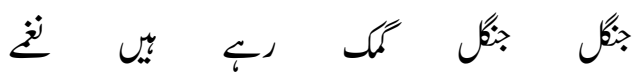

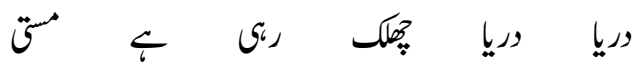

ز

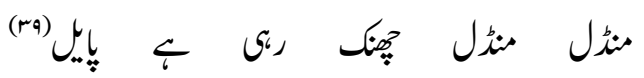

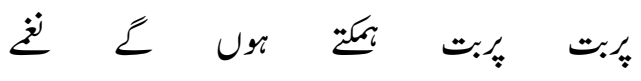

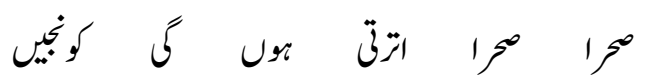

41 


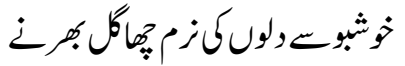

$$
\begin{aligned}
& \text { آستول }
\end{aligned}
$$

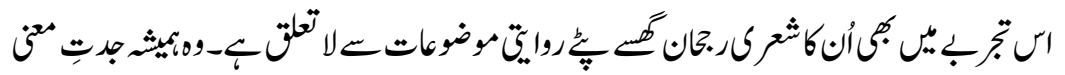

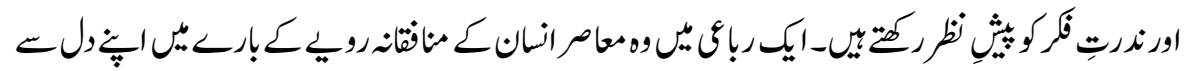

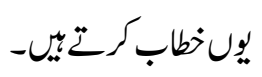

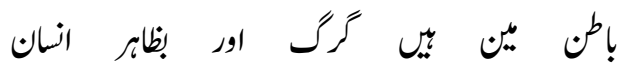

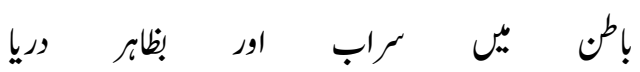

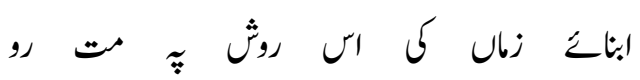

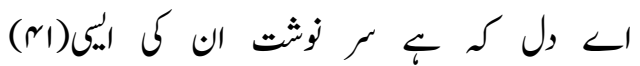

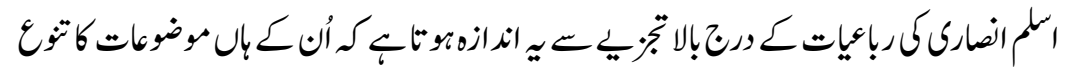

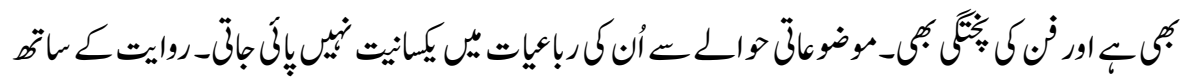

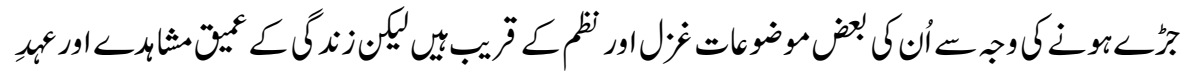

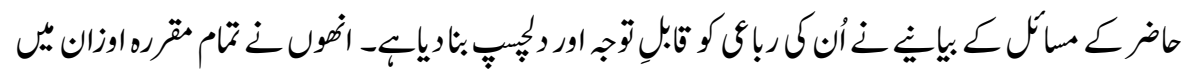

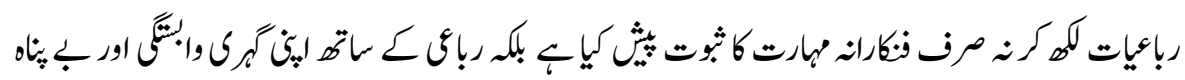

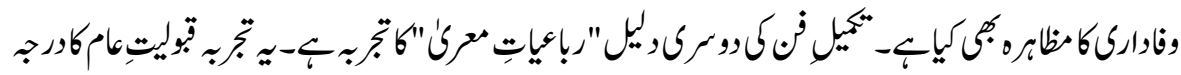

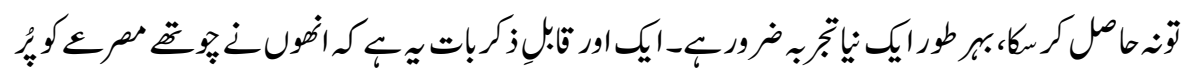

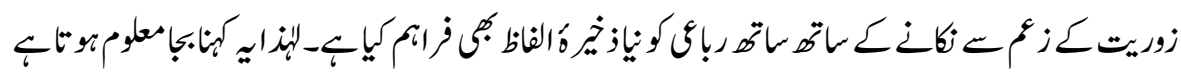

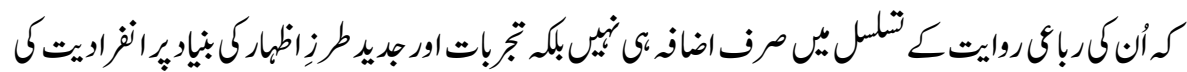




\section{والرجات}

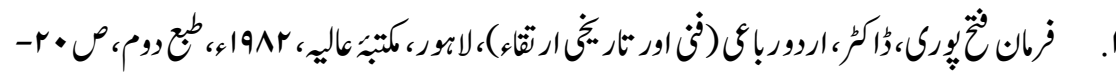

rI

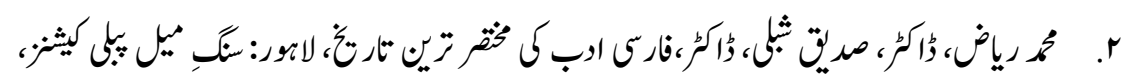

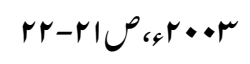

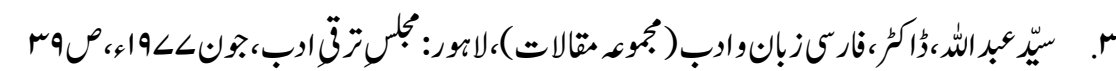

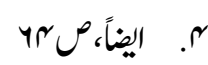

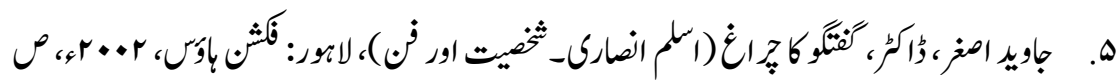

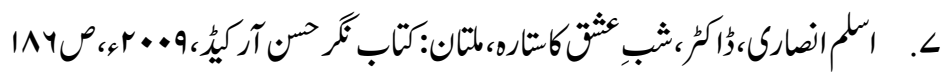

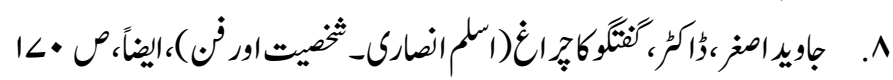

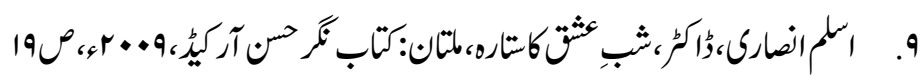

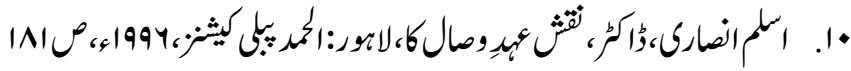
1. اليضاً، صTI Ir

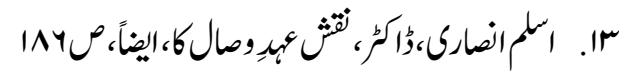
rا. اليضاً،

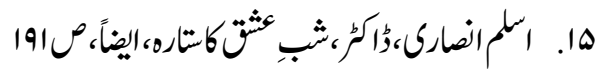

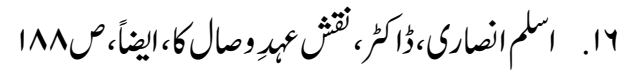

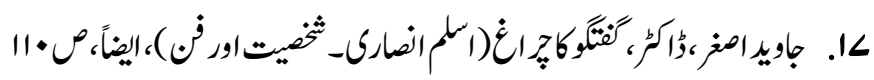

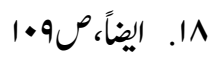
19. اليضاً 


$$
\begin{aligned}
& \text { •+. اليضاً، صـا•1 } \\
& \text { اr. اليضاً، صهُ 1 }
\end{aligned}
$$

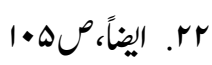

$$
\begin{aligned}
& \text { س. اليضاً، ص• } 11
\end{aligned}
$$

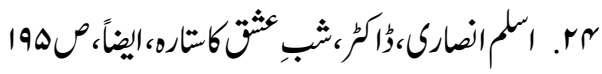

$$
\begin{aligned}
& \text { ه. اليضاً، ص194 }
\end{aligned}
$$

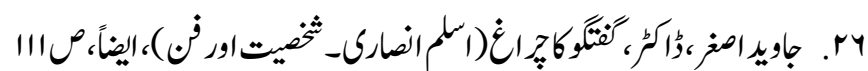

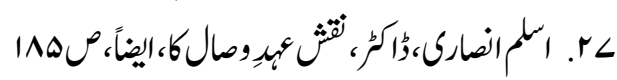$$
\text { 1. اليضاً، الصهAا }
$$$$
\text { هr. اليضاً، لـrar }
$$

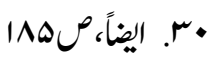

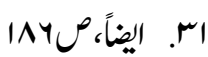$$
\text { rr. }
$$

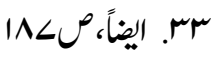

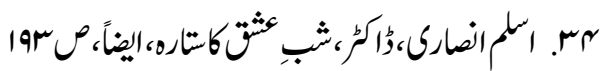

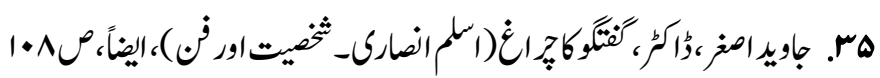

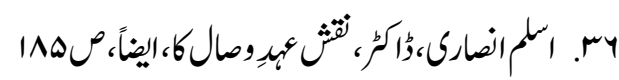

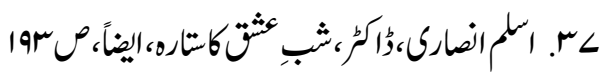

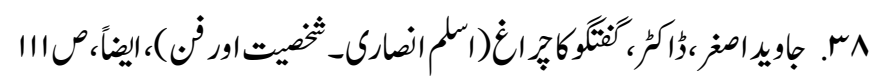

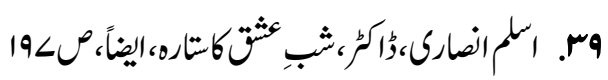
• • 191. اليضاً، ابم. اليضاً، 199 